\title{
The Quest for New Theoretical Logics of Digital Innovation: Linking Properties of Digital Artifacts with their Conceptualizations in Organizations
}

\author{
Michal Hron \\ Aarhus BSS, Denmark \\ hron@mgmt.au.dk
}

\begin{abstract}
In order to develop theories of digital innovation, it is necessary to explicitly consider the digital artifact that lends digital innovation its distinguishing features. Recent theoretical contributions elaborate the distinguishing properties of digital artifacts. These contributions have, however, not yet been systematically connected with conceptualizations that are used to frame empirical studies.

A systematic review of empirical studies in Information Systems literature on digital innovation is conducted with a focus on how digital artifacts are being conceptualized. The paper contributes by discussing how each of the four conceptualizations enable the demonstration of a particular property of digital artifacts. This summary results in a meta-theory of artifacts in digital innovation. Based on this, a research agenda is constructed, with questions that would lead us closer to finding new theoretical logics of digital innovation.
\end{abstract}

\section{Introduction}

Research on digital innovation has been presented as a quest to articulate new theories. The received wisdom on pre-digital innovation is deemed insufficient [5] and senior scholars urge us to "reinvent innovation" [31] and find new theoretical logics [31] in response to the realities of digital innovation that represent a paradigm shift [31, 57].

Fortunately, together with the demand to theorize digital innovation, a stream of fundamental work has produced increasingly refined theories of digital artifacts' properties [18, 38] such as their distributability, openness, and interactivity. These properties provide possible building blocks of the elusive "new theoretical logics" of digital innovation. However, empirical work on digital innovation makes use of a set of conceptualizations of digital artifacts that provides conceptualizations of digital artifacts suitable for organizational level analysis.
Prior literature has established four dominant conceptualizations of digital artifacts: (1) digital artifacts as a kind of resource [50], (2) digital artifacts as a stock of 'options to-be-unlocked' [54], (3) digital artifacts as a particular type of knowledge [38], or digital artifacts as a (4) facilitator of a service [3] (products-in-use). It is, however, not clear how these conceptualizations reflect properties elaborated in the theories of digital artifacts, such as distributability, openness or interactivity. By extension, it is not clear how each of the conceptualizations can be conductive to revealing the new theoretical logics of digital innovation.

The position in this paper is that research is more likely to articulate new theories of digital innovation if scholarship reflects the fundamental perspectives on digital artifacts [41]. Conversely, it will be difficult to find new theories of digital innovation without a link between empirical work and the fundamental theories of digital artifacts. After all, without digital artifacts and their novel properties, old theories of innovation would suffice.

It has been ten years since the initial theoretical works elaborating properties of digital artifacts were published $[9,24]$. With a decade of empirical work behind us, a literature review of the accumulated empirical work on digital innovation is in order, to evaluate the correspondence between the fundamental work on digital artifacts with empirical work on digital innovation.

Reviews of literature on digital innovations have been published and we will examine them next $[19,49]$. In this paper, however, we approach the literature with a specific and very different aim than that of previous reviews. We are interested in relying on the extant body of empirical work to gain understanding of how digital artifacts are conceptualized in organizations. Moreover, we are interested in understanding how useful different conceptualizations are for surfacing and elaborating specific properties of digital artifacts. The research question is: Which properties of digital artifacts does each conceptualization of digital artifacts uncover?

Thus, this paper contributes by developing a muchneeded link between the (mostly) theoretical work on 
digital artifacts and studies on digital innovation. By taking stock of existing literature in IS, the paper can provide an assessment of the progress of the search for new theoretical logics for digital innovation. Moreover, the analysis results in a meta-theory [4] of the conceptualizations that are being used to develop a nuanced view of technological artifacts in digital innovation. Such meta-theory allows for "synthesis of multiple theories within a nomological framework for simultaneously understanding them" [4:20] We discuss what each of the conceptualizations teaches us about digital artifacts and what future research questions informed by the conceptualizations and theories of digital artifacts may look like.

The paper proceeds by first outlining two relevant literature streams. The first concerns properties of digital artifacts, while the second concerns the dominant conceptualizations of digital artifacts in organizations. After describing the method, we present results that link the conceptualizations of digital artifacts with their properties through analysis of empirical literature. Based on the analysis, we offer a research agenda that could bring us nearer to closing gaps between the digital artifact and organizational reality of digital innovation.

\section{Theoretical background}

\subsection{Digital Innovation}

Digital innovation can be defined as the "carrying out of new combinations of digital and physical components" [57]. Different authors recognize the need to acknowledge the digital artifact in developing understanding of digital innovation $[1,31,56]$. Similar to our approach, Yoo et al [57] acknowledge the role of specific properties of digital technologies when they point out properties of reprogramability, self-reference and homogenization of data as the properties that give rise to layered modularity and ultimately "new organizing logic" of digital innovation. Nambisan et al., in their widely cited editorial, also direct our attention to digital technologies, specifically to their "affordances and constraints" [31], which they present as one of the four "new logics of digital innovation".

Besides conceptual papers, the work on digital innovation has been summarized in literature reviews, two of which stand out. The first review by Vial [49] systematized 282 publications across disciplines and inductively derived a thematic overview. A second review of digital innovation by Kohli and Melville [19], on the other hand, is limited to papers within the IS Basket of Eight (similar to our approach). Kohli and Melville approach their review deductively and discuss the extant findings as they relate to stages of the innovation process.
Neither of the two reviews pays particular attention to the properties of digital artifacts. We argue that that the "new theoretical logics" of digital innovation stem from properties of digital artifacts. Therefore, this paper will place them at the center of our review of the literature on digital innovation. Reviewing the various ways on which digital artifacts are conceptualized can take us to the root of digital innovation and hence lead to a contribution to the core of the digital innovation literature.

\subsection{Technological Artifact in IS research}

The assertion that the technological object (digital artifact) needs to be considered for IS scholarship on digital innovation to develop faithful theories of its subject is not new. It finds precedence in calls for explicit treatment of the technological artifact dating back to Orlikowski and Iacono in 2001 [34], who initially tallied the ways in which the technological artifact is represented in research. Their results showed that only $12.5 \%$ of published papers represent the artifact with a nuanced "Ensemble view" that attends to the web of relationships in which technologies are embedded. The proportional share of publications which portray the technological artifact thus across major IS journals remained similarly low when different authors later duplicated Orlikowski and Iacono's analysis [38].

Nineteen years after Orlikowski and Iacono's analysis, a significant portion of IS scholarship is devoted to digital innovation. However, the digital artifacts currently discussed are different from the IT artifacts of earlier days [18] and their role in organizing economic activity has also shifted [42]. Digital artifacts and their non-material nature [24] have been extensively theorized, as we review next.

\subsection{Properties of digital artifacts}

Digital artifacts rely on material components [38], but their novelty lies in their non-materiality. Hui understands digital artifacts as objects that "take shape on a screen or hide in the back end of a computer program, composed of data and metadata regulated by structures or schemas" [16]. We largely subscribe to this definition in this review. Archetypical examples of such digital artifacts are "computer bugs", a profile on a social media website [9], or - more broadly — data [16].

Digital artifacts and their properties have been a subject of a relatively recent stream of theorizing $[9,17$, 38]. Kallinikos et al [18] provide a high-level overview of the cross-disciplinary debate by summarizing the discussed properties of digital artifacts as: 
distributability, editability/interactivity, and openness/reprogramability.

2.3.1. Distributability: Digital artifacts are duplicable and transferable. They can "freely diffuse throughout organizational fabric" [17]. Seen as distributable, digital artifacts can be an input for combinatorial innovation [15].

2.3.2. Editability/interactivity: Digital artifacts can be dynamically assembled and reassembled at will. As a result, the same artifact can adopt to different contexts [6] and take on a new meaning, either by being materially reconstituted or re-interpreted [10]. Thanks to editability, individuals can change the technology according to knowledge, norms, and rules [33]. Related to editability, Kallinikos et al. also distinguish interactivity which differs from editability in that it does not lead to change in the artifact itself. Interactivity can be thought of as a distinct form of editability because both editability and interactivity enable actions of contingent nature [6]. This paper brings these two constructs closer together.

2.3.3. Openness/reprogramability: Digital artifacts are open and generative [54]. They can form software platforms [47], providing a baseline for further development. As such, they can be seen as incomplete by design [11], and thus their meaning can evolve as they are extended or reinterpreted [9].

Those properties have been developed with some basis in empirical work, but their integration with theories of digital innovation has been limited. This may be because, although fundamental, their application in empirical work is not always intuitive and authors rely on a separate set of conceptualizations to describe digital artifacts in organizations.

\subsection{Conceptualizations of Digital artifacts in Organizations}

While the theories of digital artifacts provide an increasingly layered debate of digital artifacts, a separate set of conceptualizations have been used to conceptualize the digital artifacts in organizations. Those theories offer conceptualizations of digital artifacts that lend themselves more readily to analyzing the influence of digital artifacts on individual use, functioning of teams, mechanisms of organizations, metabolism of ecosystems, or the heartbeat of whole industries.

Faulkner and Runde [38] critically review three families of conceptualizations of digital artifacts in organizations: (1) digital artifacts as resources, (2) digital artifacts as knowledge and (3) conceptualization in line with service-dominant logic. A fourth conceptualization sees (4) digital artifacts as design capital [54]. As a comment to the first three conceptualizations, Faulkner and Runde note that all three "devote considerably more attention to IT-related competences in the form of managerial and technical knowledge, skills and processes, than they do to the devices involved" (p. 1282). This comment could apply to the fourth conceptualization as well. Nevertheless, since these views drive much of current literature, we review them next.

2.4.1. Digital artifacts as resources: typically drawing on the resource-based view [50], digital artifacts in organizations can be seen as resources from which competitive advantage is derived. Specific concepts can be brought up, such as network resources [36] or IT resources [50]. As a stark departure from the view of resources as being difficult to difficult to imitate and transfer [28], much theory development is needed for the digital innovation context.

2.4.4. Digital artifacts as design capital: theories in this family draw on real options theory [39, 54], where the stock of digital artifacts in a company can be valued through a bundle of options that it can unlock. For example, when a company invests in digital artifacts (e.g. into digital infrastructure), the real options view would argue that although the infrastructure may not be valuable per se, its value is in the potential to enable the development of features or applications on top of it.

2.4.2. Digital artifacts as knowledge: drawing on knowledge management theories [32] or sociocognitive perspectives such as sensemaking [26], digital artifacts can be seen as a form of knowledge. One way of seeing digital artifacts as knowledge is to invoke the idea of externalized knowledge and understand knowledge as electronic records (explicit knowledge) [32]. Alternatively, we can see digital competences as a form of knowledge a company needs to acquire to be able to manipulate the technology (tacit knowledge). Since knowledge can reside within individuals or be externalized [32], this perspective provides perhaps the most flexible framework.

2.4.3. Digital artifacts as products-in-use: frequently drawing on service-dominant logic [3], digital artifacts can be seen as a medium for delivery of a service, which is suitable to their non-material character [24]. Servicedominant logic offers a theoretical reflection on the nature of materiality. Operant or operand resources have been distinguished [2]. Operand resources just enable action (and are typically understood as material), whereas operant resources initiate action (and are typically seen as non-material) [2]. Thus, the focus of SD logic is on the experience of (immaterial) service delivery where digital artifacts are just enablers. Yoo's framework on experiential computing [55] provides a similarly phenomenological conceptualization of digital artifacts. 


\section{Method of literature review}

Since our aim is to link the perspective elaborating the properties of digital artifacts with organization-level conceptualizations, we relied on the extant corpus of empirical studies and decided to carry out a literature review. We have followed a widely accepted procedure for conducting systematic reviews of literature [51]. The analytical process unfolds in five distinct stages.

First, a search query was executed in late June 2020 on the Scopus database for the word "innovation" in abstract, title or keywords in all eight "Basket of Eight". journals. We limited the search to the Senior Scholars' Basket of Eight because we were interested in the treatment of digital innovation from the IS perspective. The initial query returned 552 papers.

Second, we limited the results to papers published from 2011 onwards because that is when the earliest theoretical papers $[9,17]$ on digital artifacts started appearing, and we could expect to see them reflected in the papers. The year filter left us with 263 papers.

\section{Table 1: Literature review process}

\begin{tabular}{|c|l|c|}
\cline { 2 - 3 } \multicolumn{1}{l|}{} & \multicolumn{1}{|c|}{ Stage Description } & $\begin{array}{c}\text { Papers } \\
\text { left }\end{array}$ \\
\hline 1. & $\begin{array}{l}\text { Initial search in the Basket of } 8 \\
\text { for "innovation" }\end{array}$ & 552 \\
\hline 2. & Limit to papers after 2010 & 263 \\
\hline 3. & $\begin{array}{l}\text { Initial screening. Limit to } \\
\text { empirical papers. }\end{array}$ & 200 \\
\hline 4. & $\begin{array}{l}\text { Limit to papers that explicitly } \\
\text { consider digital artifacts. }\end{array}$ & 53 \\
\hline
\end{tabular}

Third, we conducted initial screening of the papers to eliminate non-empirical work (reviews, conceptual papers, editorials etc.) because we explicitly aimed to review empirical papers. This resulted in a collection of 202 papers.

Fourth, we sorted our sample using the different views of the technological/digital artifact following Orlikowski and Iacono [34]. We were only interested in papers that provided a sophisticated view of the digital artifact, i.e. those which adopted the ensemble view [34]. 53 papers from the previous step satisfied this criterion and therefore formed our final sample.

Since this kind of analysis has been conducted by several authors since Orlikowski and Iacono [38], we could rely on those papers for process notes and for a wealth of examples. The previous research finds that a fairly consistent proportion of articles attend to the technological artifact with the nuance of the ensemble view. Our analysis found a share of papers consistent with the previous findings.
In the fifth step, we analyzed the 53 papers with respect to which properties of digital artifacts were addressed [18] and what dominant conceptualization of digital objects was adopted [17].

Fortunately, the extant theoretical work provides plentiful examples against which the presence of the properties can be assessed [18, 38] which, through careful reading of the manuscript, was helpful in determining which properties were addressed.

Similarly, the assessment of which conceptualization was used was done by close reading of the papers, with attention to the highlighted theoretical notions. For example, the resource view is revealed by ideas of competitive advantage. Notions like path dependence are indicative of thinking in terms of design capital.

\section{Results}

\subsection{Descriptive results}

The number of publications was quite evenly distributed across the studied years (from 2011 to 2020, see Figure 1 and Table 2). While the overall volume of publications on digital innovation has been growing [49], our sample is restricted to the Basket of Eight, where the topic of digital innovation seems to occupy a relatively constant share of attention. We cannot, for example, say that the topic of digital innovation took up increasingly more space in the Basket of Eight journals.

Table 2: Papers across journals

\begin{tabular}{|l|c|c|}
\hline \multicolumn{1}{|c|}{ Journal } & $\begin{array}{c}\text { Hits after } \\
\mathbf{2 0 1 0}\end{array}$ & Final sample \\
\hline EJIS & 32 & 5 \\
\hline ISJ & 26 & 6 \\
\hline ISR & 38 & 5 \\
\hline Journal of IT & 26 & 8 \\
\hline Journal of MIS & 27 & 1 \\
\hline JSIS & 35 & 5 \\
\hline Journal of AIS & 36 & 9 \\
\hline MIS Quarterly & 43 & 10 \\
\hline Total & 263 & 53 \\
\hline
\end{tabular}

Note: First column corresponds to stage 2 in Table 1, Second column corresponds to stage 4 in Table 1

Before analyzing the 53 papers that consider the technological artifact in detail (stage 4 in the method section, Table 1), it is worth remarking on the how the literature on digital innovation literature treats the 
artifact more broadly (using literature from stage 3 of the method section).

In coding the papers following the categories of how the technological artifact is conceptualized from Orlikowski and Iacono [34], we found the greatest number of papers only mentioned the digital artifact (nominal view) without explicitly conceptualizing or defining it. We counted 71 such papers. As an example of such a conceptualization, consider a paper [35] which discusses the role of familiarity of advisory services on innovation outcomes, with only passing mention of the context of information technologies.

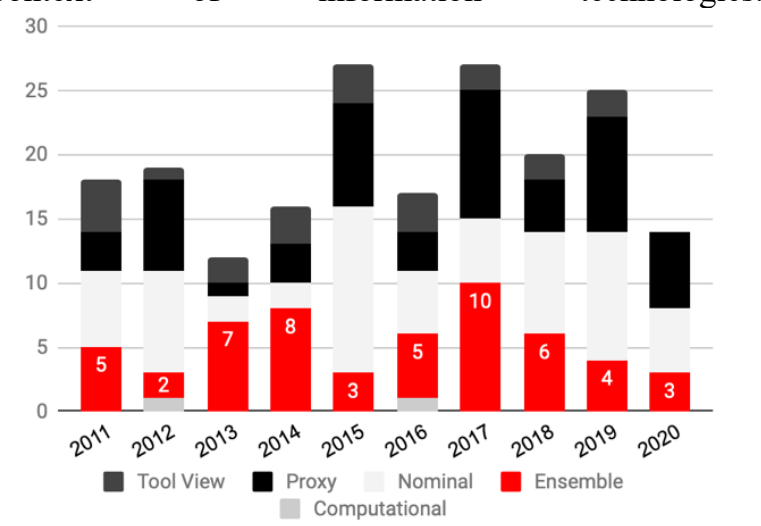

Figure 1: Literature over time according to view of technological artifact following [34]

The second most common conceptualization is the proxy view, used by 53 papers in the sample. A typical example of a proxy of digital artifacts in a company is the number of digital patents [14] in examining digital mergers and acquisitions. Proxies are generally common in quantitative work, that uses surveys.

Tied for second place, 53 more papers considered the digital artifact with the refined view that Orlikowski, and Iacono term the "ensemble view". The ensuing analysis will provide a plethora of examples.

Lastly, 21 of the sample papers conceptualized digital artifacts as tools. This is typical in research examining technology adoption at work such as when researchers examine IT as a tool for workplace learning [48]. Just two papers saw digital artifacts as computational objects (algorithms).

Ultimately, we found that $20 \%$ of the publications in the Basket of Eight published after 2010 satisfied our criteria, which is in line with previous findings of other authors who have duplicated the analysis by Orlikowski and Iacono $[16,40]$. We analyze the 53 papers in the ensemble view next.

\subsection{How do the conceptualizations reflect properties of digital artifacts}

Our analysis confirmed wide use of the four prevailing conceptualizations of digital artifacts discussed above in organizations. Table 3 provides a numerical overview of results and an outline for our analysis. Each of the four conceptualizations unearths different set of dynamics stemming from the properties of digital artifacts and finds use for particular instances of digital innovation. We will continue to discuss each of the conceptualizations, noting what its extant use for empirical work can teach us about digital innovation and its new theoretical logics.

Table 3: Meta-Theory of Digital Innovation: Conceptualizations vs. properties of digital artifacts

\begin{tabular}{|l|c|c|c|c|}
\cline { 3 - 5 } \multicolumn{2}{c|}{} & \multicolumn{3}{c|}{ Properties of digital artifacts } \\
\hline $\begin{array}{l}\text { Dominant } \\
\text { conceptualization }\end{array}$ & $\begin{array}{c}\text { Papers invoking } \\
\text { conceptualization }\end{array}$ & Distributability & $\begin{array}{c}\text { Openness/ } \\
\text { reprogramability }\end{array}$ & $\begin{array}{c}\text { Editability/ } \\
\text { Interactivity }\end{array}$ \\
\hline Digital Resource & 18 & 15 & 11 & 5 \\
\hline Design Capital & 13 & 8 & 11 & 7 \\
\hline Knowledge & 13 & 12 & 6 & 5 \\
\hline Product-in-use & 9 & 4 & 4 & 5 \\
\hline Total & 53 & 39 & 32 & 22 \\
\hline
\end{tabular}

Note: Numbers give a count of papers that adopt a conceptualization (row) and address each of the three fundamental properties (columns). A single paper can address multiple properties.

5.2.1 Design Capital: When digital artifacts are seen through the design capital lens, their generative potential (i.e.; openness) gets appreciated more than other properties. Digital artifacts can be extended into many new, unanticipated directions and investments in fundamental infrastructure can be valued for the options which they enable later on. Empirical work reveals the challenges associated with developing some of the new options. The role of technical debt is brought to the surface [37]. Sometimes, the generative 
design capital can be bypassed and solutions can be "grafted" on top of it [40]. In other cases, the stock of design capital is plagued with technical debt and needs to be replaced [27].

The design capital view has been explicitly theorized $[39,54]$ even though it is sometimes invoked implicitly. Notions like path dependence, path constitution [46], or extensions of existing architectures [40] are often indicative of thinking of digital artifacts as a form of design capital.

This perspective finds its use especially in company-level analysis, but also for studying ecosystems of actors organized around an artifact that provides a bundle of options for a host of interlinked actors.

5.2.2 Digital Resource: Thinking about the resources of organizations has a long tradition in management scholarship. Even within IS, notions like IT resources have been an anchor of much work [50]. However, new dynamics are unearthed when digital artifacts are considered as resources. This particularly concerns the fact that they can be duplicated and transferred at virtually no cost (i.e. distributability). As a particularly stark example of a break from the old view of resources as rare and inimitable, some companies embrace openness and distributability and strategically make their digital artifacts available as open source [30].

The idea of distributable resources is especially apparent in platform ecosystems with notion of "boundary resources" [8], defined as "software tools and regulations that serve as the interface for the arm'slength relationship between the platform owner and the application developer" (p.176). This aptly captures the view of resources than can span organizations and need to be negotiated among ecosystem actors [12, 45]. A similar concept, network resources, speaks to a similar dynamics, while also implicitly drawing on the tradition of the resource-based view [36:596].

The resource-based view on strategy is therefore clearly upended with digital resources. In line with its theoretical roots, this perspective is most used in the analysis of companies and their competitive positioning (which may be within broader ecosystems).

5.2.3 Knowledge Perspective: Seeing digital artifacts as knowledge opens up a broad set of flexible theoretical approaches. Concepts from knowledge management theories [32] or socio-cognitive perspectives like sensemaking are employed [26]. With knowledge management theories, some authors, for instance [20], leverage the notion of absorptive capacity to arrive at "refined theory on absorptive capacity regarding business model change resulting from the emergence of disruptive digital technologies “ (p. 500).

Digital artifacts are seen as tools that can facilitate organizational learning in communities involving participants within and across organizations [43]. However, digital artifacts do not just provide the tools for managing knowledge; they can also be the knowledge itself [21]. The knowledge view aims to capture the multiple characteristics of digital artifacts [21], especially distributability. It can also often shed light on the interconnectedness of digital artifacts and the organization [29] of where digital artifacts can do things like redefine established roles [53].

In sum, the knowledge perspective reveals in particular distributability and openness. The perspective is applied in a wide range of units of analysis. However, it often relies on established theoretical concepts, which may be limiting in developing unique theories for digital innovation.

5.3.4. Product-in-use: The immateriality of digital artifacts makes it possible to think of them in terms of the service they enable. In doing so, the discourse on service-dominant logic is often invoked [23:446]. The notion of affordances can be applied [25]. Digital artifacts here recede into the background in favor of a phenomenological account. Moreover, this perspective reveals digital artifacts as more than material to-be-manipulated. They are revealed as actants which can influence the course of action. For example, a cleverly designed carbon management system [7] can steer employees into behaving more ecologically. Lastly, the notion of co-creation is often a focus. The notion between creation and consumption is blurred [22].

This perspective is employed by individual users as a level of analysis when discussing the design process of digitally delivered experiences.

\section{Discussion}

Throughout the reviewed sample of literature, four conceptualizations of digital artifacts in organizations have been identified, each particularly suitable for revealing one property of digital artifacts in particular. Thus, when digital artifacts are seen as design capital, emphasis is placed on their openness. When digital artifacts are conceptualized as resources, their distributability is often brought to bear. When digital artifacts are conceptualized as product-in-use, their editability is often emphasized. Lastly, when digital artifacts are conceptualized as a form of knowledge distributability is particularly highlighted.

This review analyzed literature on digital innovation with respect to how digital artifacts are operationalized in empirical studies and how these 
conceptualizations reflect the distinguishing properties of digital artifacts.

Overall, we uncover a literature where only about a fifth $(18 \%)$ of the total published articles present a refined portrayal of the technological artifact in its organizational context. This proportion is in line with what has been tallied in previous analyses duplicating the pioneering work of Orlikowski and Iacomo [38]. On a positive note however, while the IS discipline has been critiqued for over-reliance on borrowed theories that do not explicitly consider the digital artifact [13], the conceptualizations used in our sample of empirical papers on digital innovations are either native to IS (e.g. the design capital logic of business strategy [54]) or meaningfully adapt inherited concepts (e.g. distributable resources [8] as an adaptation of the resource-based view). In what follows, I construct a research agenda consisting of research questions that could enrich the four conceptualizations to better reflect the properties of digital artifacts in the search for new, richer, theories of digital innovation.

\section{Table 4 Possible Research Questions}

\begin{tabular}{|c|c|}
\hline $\begin{array}{l}\text { Design } \\
\text { capital }\end{array}$ & $\begin{array}{l}\text { When companies work on unlocking a set of design capital options, how should they organize } \\
\text { around the artifact (within company or across the ecosystem)? } \\
\text { - How are decisions made about how to present the new options ? When should new or old } \\
\text { product identities be favored? What is the role of the open digital artifact in the process? } \\
\text { - What is the role of openness and distributability in managing design capital } \\
\text { (and motions like forking)? } \\
\text { - When should decisions support abandoning an existing design capital in favor of fresh } \\
\text { development? }\end{array}$ \\
\hline $\begin{array}{l}\text { Digital } \\
\text { resource }\end{array}$ & $\begin{array}{l}\text { How can companies attain competitive advantage when digital resources can be duplicated, } \\
\text { edited, or freely distributed? } \\
\text { - What kind of digital resources and associated practices facilitate generativity and attract other } \\
\text { actors when companies try to orchestrate an ecosystem? } \\
\text { How can the meaning of digital resources as resources be stabilized given their open-ended } \\
\text { nature (editability, openness)? }\end{array}$ \\
\hline Knowledge & $\begin{array}{l}\text { - What new dynamics in organizational learning and knowledge management are enabled by the } \\
\text { unique distributability and editability of digital artifacts? } \\
\text { - How are previously theorized socio-cognitive processes affected by properties of digital } \\
\text { artifacts? How does that affect innovation? } \\
\text { - How is organizational learning impacted by distributable digital artifacts? } \\
\text { - How do digital artifacts enable new organizational arrangements? }\end{array}$ \\
\hline $\begin{array}{l}\text { Product- } \\
\text { in-use }\end{array}$ & $\begin{array}{l}\text { - How can companies leverage editability of digital artifacts and design for co-creation? } \\
\text { - } \quad \text { How can consistent product identity be ensured/managed when digital objects can be distributed } \\
\text { and locally interpreted? } \\
\text { - } \quad \text { How can threats of piracy stemming from distributability/reuse of digital artifacts be managed? }\end{array}$ \\
\hline
\end{tabular}

\subsection{Research Agenda}

From the meta-theory [4] presented in Table 3, different avenues for future research can be derived. In addition to the theoretical motivation, some questions are driven by a desire to ground some of the theoretical abstractions somewhat by introducing some practical concerns that the theories abstract away.

\subsubsection{Questions about Digital Artifacts as Design} capital: Design capital has already demonstrated the openness and (to some extent) distributability of digital artifacts. How does interactivity and editability of digital artifacts manifest itself, when they are seen as a form of capital?
Since the conceptualization of artifacts as a stock of capital derives from an economic perspective on real options, it starts relatively far from a practice perspective [54]. Imagine for instance a company that owns a stock of design capital and wishes to execute an extension of it. As an immediate practical concern, it is not clear what organizational arrangements are suitable for unlocking the options. Should it be the same organization? A sub-unit? Similarly, if the options tobe-developed concern new user-facing features, it is not clear how or when they should be presented as a part of the old product and when a new product identity (branding) is suitable.

From the standpoint of theories of digital innovation, investigating the role of openness [18] and distributability leads to additional research avenues. For 
instance, more could be known about operations uniquely enabled by digital artifacts such as forking (duplication of design capital). Lastly, on the topic of "technical debt"'[27], which serves as an additional cost to unlocking certain options, not much is known about decisions to abandon design capital in favor of fresh development. How are these decisions made and how are they managed?

6.1.2. Questions about Digital Resources: Digital artifacts as resources are described as open and distributable. It is less clear how editability and interactivity manifest themselves in this view.

How can companies attain competitive advantage when digital resources can be duplicated, edited, or freely distributed? Starting from the premise that generativity is at the core at digital innovation, what kind of digital resources and associated practices facilitate generativity and attract other actors when companies try to orchestrate an ecosystem? Pursuing the properties of editability and interactivity could lead us to an individual level of analysis, which is less common with the resource conceptualization.

However, a problem with openness of resources for cocreation may lead to challenges stemming from a loss of control. We know that digital artifacts can be reinterpreted or re-assembled (edited). A theoretical as well as managerial concern may arise over how the meaning of digital artifacts as resources can be stabilized and negotiated.

6.1.3. Questions about Digital Artifacts as Knowledge: When empirical research on digital innovation leverages the knowledge perspective, pertinent questions relate to the unique dynamics of organizational learning, which are enabled by digital technologies and their specific properties. Knowledge management is a well-researched area [44] but since digital artifacts display new properties [16] and because their role in organizations has shifted $[42,52]$, revision of these perspectives in the context of digital innovation may be a worthwhile pursuit. For example, how is organizational learning impacted by distributable digital artifacts? Could it serve as a catalyst of learning, or as a source of fixation? Are other cognitive theories, like sensemaking, impacted by interactive and distributable digital artifacts?

The research avenues for digital innovation from the knowledge perspective are also tightly linked with organizational matters. For instance, since digital innovations occur at the intersection of multiple traditional departmental areas, we may inquire into the role of specialization. How can digital artifacts be used to foster cross-disciplinary collaboration?

6.1.4 Questions about Digital Artifacts as Productin-use: When digital artifacts are seen as products-inuse, investigated topics concern interactions between the user and the product. How are the digital products themselves recombined? How are the identities of digital artifacts negotiated (destabilized and stabilized)? As such, editability/interactivity is highlighted. A line of inquiry of great relevance to practitioners concerns how these unbounded interactions between networks of cocreators and consumers can be managed. In such settings, the questions of how identity of editable/interactive products is negotiated stands at the center of interest.

Developing research questions that address openness and distributability [18] can be beneficial. How are products experienced and extended (edited) by users? How do modifications get distributed in user networks? Another practical concern that accompanies co-creation is piracy [22], which surfaces the "dark side" of cocreation with distributable digital artifacts. This generally invites more work on the paradox between control and generativity that is enabled by editable digital artifacts.

\section{Conclusion}

The central argument of this paper, that digital artifacts need to be considered in order for the quest for new logics of digital innovation to succeed, proves the enduring value of the point raised by Orlikowski and Iacono in 2001. For the context of digital innovation, the theoretical pathways to accomplish a refined view of the digital artifact does need to be revised.

The reviewed empirical literature on digital innovation is driven by four common conceptualizations of digital artifacts which we brought together in a metatheory (Table 3). (1) Design Capital conceptualization can especially surface openness. (2) Digital Resource conceptualization is particularly effective at surfacing distributability. (3) Knowledge conceptualization focuses on distributability. Finally, (4) Product-in-use theories surfaces editability/interactivity of digital artifacts.

This paper has relied on papers discussing properties of digital artifacts [9, 18]. Those papers discuss digital artifacts as an undifferentiated whole. Therefore, the paper totalizes the diversity of digital artifacts which come with many specifics. Certainly, many digital artifacts will have unique challenges and aspects that will generate opportunities to pursue research with more specific applications, which may challenge some of the high-level assertions in theoretical works including this one.

As a further limitation of the presented work, we need to highlight our choice to limit the review to major journals. Given the timeliness of the phenomena, many contributions are being discussed at conferences or other outlets. Moreover, some of the articles in the other 
categories (like Tools) could also be informative. Focusing only on ensemble view papers is a necessary methodological limitation. However, as the major journals should present the best of IS scholarship, we believe this review represents a step towards the goal of new theoretical logics in digital innovation.

\section{References}

[1] Agostini, L., F. Galati, and L. Gastaldi, "The Digitalization of the Innovation Process: Challenges and Opportunities from a Management Perspective", European Journal of Innovation Management 23(1), 2019, pp. 1-12.

[2] Akaka, M.A., and S.L. Vargo, "Technology as an operant resource in service (eco)systems", Information Systems and e-Business Management 12, 2014, pp. 367-384.

[3] Barrett, M., E. Davidson, J. Prabhu, and S.L. Vargo, "Service innovation in the digital age: Key contributions and future directions", MIS Quarterly: Management Information Systems, 2015.

[4] Bostrom, R., S. Gupta, and D. Thomas, "A metatheory for understanding information systems within sociotechnical systems", Journal of Management Information Systems 26(1), 2009, pp. 17-48.

[5] Brown, S.L., and K.M. Eisenhardt, "The Art of Continuous Change: Linking Complexity Theory and timepaced Evolution in relentlessly shifting Organizations", Administrative Science Quarterly 42(1), 1997, pp. 1-34.

[6] Ciborra, C., and L. Willcocks, "The Mind or the Heart? It depends on the (Definition of) Situation", Journal of Information Technology 21(3), 2006, pp. 129-139.

[7] Corbett, J., "Designing and using carbon management systems to promote ecologically responsible behaviors", Journal of the Association for Information Systems 14(7), 2013.

[8] Eaton, B., S. Elaluf-Calderwood, C. Sørensen, and Y. Yoo, "Distributed tuning of boundary resources: The case of Apple's iOS service system", MIS Quarterly: Management Information Systems 39(1), 2015, pp. 217-243.

[9] Ekbia, H.R., "Digital Artifacts as Quasi-objects: Qualification, Mediation, and Materiality", Journal of the American Society for Information Science and Technology 60(12), 2009, pp. 2554-2566.

[10] Faulkner, P., and J. Runde, "On the Identity of technological Objects and User Innovations in Function", Academy of Management Review 34(3), 2009, pp. 442-462.

[11] Garud, R., S. Jain, and P. Tuertscher, "Incomplete by Design and designing for Incompleteness", Organization Studies 29(3), 2008, pp. 351-371.

[12] Ghazawneh, A., and O. Henfridsson, "Balancing platform control and external contribution in third-party development: The boundary resources model", Information Systems Journal 23(2), 2013, pp. 173-192.

[13] Grover, V., and K. Lyytinen, "New State of Play in Information Systems Research: The Push to the Edges", MIS Quarterly 39(2), 2015, pp. 271-296.

[14] Hanelt, A., S. Firk, B. Hilebrandt, and L.M. Kolbe, "Digital M\&A, digital innovation, and firm performance: an empirical investigation", European Journal of Information Systems, 2020, pp. 1-24.
[15] Henfridsson, O., J. Nandhakumar, H. Scarbrough, and N. Panourgias, "Recombination in the open-ended Value Landscape of digital Innovation", Information and Organization 28(2), 2018, pp. 89-100.

[16] Hui, Y., On the Existence of Digital Objects, U of Minnesota Press, 2016

[17] Kallinikos, J., A. Aaltonen, and A. Marton, "A theory of digital Objects", First Monday 15(6-7), 2010.

[18] Kallinikos, J., A. Aaltonen, and A. Marton, "The Ambivalent Ontology of Digital Artifacts", MIS Quarterly 41(1), 2013, pp. 357-370.

[19] Kohli, R., and N.P. Melville, "Digital innovation: A review and synthesis", Information Systems Journal 29(1), 2019 , pp. 200-223.

[20] Kranz, J.J., A. Hanelt, and L.M. Kolbe, "Understanding the influence of absorptive capacity and ambidexterity on the process of business model change - the case of on-premise and cloud-computing software", Information Systems Journal 26(5), 2016, pp. 477-517.

[21] Kyriakou, H., J. V. Nickerson, and G. Sabnis, "Knowledge reuse for Customization: Metamodels in an open Design Community for 3D printing", MIS Quarterly: Management Information Systems 41(1), 2017, pp. 315-332.

[22] Lang, K., R. Shang, and R. Vragov, "Consumer cocreation of digital culture products: Business threat or new opportunity?", Journal of the Association for Information Systems 16(9), 2015.

[23] Lehrer, C., A. Wieneke, J. vom Brocke, R. Jung, and S. Seidel, "How Big Data Analytics Enables Service Innovation: Materiality, Affordance, and the Individualization of Service", Journal of Management Information Systems 35(2), 2018, pp. 424-460.

[24] Leonardi, P.M., "Digital materiality? How artifacts without matter, matter", First Monday 15(6), 2010.

[25] Leonardi, P.M., "When flexible routines meet flexible technologies: Affordance, constraint, and the imbrication of human and material agencies", MIS Quarterly: Management Information Systems, 2011, pp. 147-167.

[26] Lewis, M.O., L. Mathiassen, and A. Rai, "Scalable growth in IT-enabled service provisioning: A sensemaking perspective", European Journal of Information Systems 20(3), 2011, pp. 285-302.

[27] Mehrizi, M.H.R., J.R. Modol, and M.Z. Nezhad, "Intensifying to cease: Unpacking the process of information systems discontinuance", MIS Quarterly: Management Information Systems 43(1), 2019, pp. 141-165.

[28] Melville, N., K. Kraemer, and V. Gurbaxani, "Review: Information technology and organizational performance: An integrative model of it business value", MIS Quarterly: Management Information Systems 28(2), 2004, pp. 283-322.

[29] Montazemi, A.R., J.J. Pittaway, H. Qahri Saremi, and Y. Wei, "Factors of stickiness in transfers of know-how between MNC units", Journal of Strategic Information Systems 21(1), 2012, pp. 31-57.

[30] Morgan, L., and P. Finnegan, "Beyond free software: An exploration of the business value of strategic open source", Journal of Strategic Information Systems 23(3), 2014, pp. 226-238.

[31] Nambisan, S., K. Lyytinen, A. Majchrzak, and M. Song, "Digital Innovation Management: Reinventing 
Innovation Management Research in a Digital World", MIS Quarterly 41(1), 2017, pp. 223-238.

[32] Nonaka, I., R. Toyama, and N. Konno, "SECI, Ba and Leadership: A Unified Model of Dynamic Knowledge Creation", Long Range Planning 33(1), 2000, pp. 5-34.

[33] Orlikowski, W.J., "Using Technology and Constituting Structures: A Practice Lens for Studying Technology in Organizations", Organization Science 11(4), 2000, pp. 404-428.

[34] Orlikowski, W.J., and C.S. Iacono, "Research Commentary: Desperately Seeking the 'IT' in IT Research - A Call to Theorizing the IT Artifact", Information Systems Research 12(2), 2001, pp. 121-134.

[35] Oshri, I., D. Arkhipova, and G. Vaia, "Exploring the effect of familiarity and advisory services on innovation outcomes in outsourcing settings", Journal of Information Technology 33(3), 2018, pp. 203-215.

[36] Rehm, S.V., L. Goel, and I. Junglas, "Using information systems in innovation networks: Uncovering network resources", Journal of the Association for Information Systems 18(8), 2017, pp. 577 - 604.

[37] Rolland, K.H., L. Mathiassen, and A. Rai, "Managing digital platforms in user organizations: The interactions between digital options and digital debt", Information Systems Research 29(2), 2018, pp. 419-443.

[38] Runde, J., and P. Faulkner, "Theorising the Digital Object”, MIS Quarterly 43(4), 2019, pp. 1-24.

[39] Sambamurthy, V., A. Bharadwaj, and V. Grover, "Shaping Agility through Digital Options: Reconceptualizing the Role of Information Technology in Contemporary Firms", MIS Quarterly 27(2), 2004, pp. 237-263.

[40] Sanner, T.A., T.D. Manda, and P. Nielsen, "Grafting: Balancing control and cultivation in information infrastructure innovation", Journal of the Association for Information Systems 15(special issue), 2014, pp. 220-243.

[41] Sarker, S., S. Chatterjee, X. Xiao, and A. Elbanna, "The sociotechnical axis of cohesion for the IS discipline: Its historical legacy and its continued relevance", MIS Quarterly: Management Information Systems 43(3), 2019, pp. 695-720.

[42] El Sawy, O.A., "The IS Core IX: The 3 Faces of IS Identity: Connection, Immersion, and Fusion", Communications of the Association for Information Systems 12, 2003, pp. 588-589.

[43] Schlagwein, D., and N. Bjørn-Andersen, "Organizational Learning with Crowdsourcing: The revelatory Case of LEGO", Journal of the Association for Information Systems 15(11), 2014.

[44] Schultze, U., and D.E. Leidner, "Studying knowledge management in information systems research: Discourses and theoretical assumptions", MIS Quarterly:
Management Information Systems 26(3), 2002, pp. 213-242.

[45] Selander, L., O. Henfridsson, and F. Svahn, "Capability search and redeem across digital ecosystems", Journal of Information Technology 28(3), 2013, pp. 183-197.

[46] Singh, R., L. Mathiassen, and A. Mishra, "Organizational path constitution in technological innovation: Evidence from rural telehealth", MIS Quarterly: Management Information Systems 39(3), 2015, pp. 643-665.

[47] Tiwana, A., B. Konsynski, and A.A. Bush, "Platform Evolution: Coevolution of Platform Architecture, Governance, and environmental Dynamics", Information Systems Research 21(4), 2010, pp. 675-687.

[48] Torkzadeh, G., J.C.J. Chang, and A.M. Hardin, "Usage and impact of technology enabled job learning", European Journal of Information Systems 20(1), 2011, pp. 6986.

[49] Vial, G., "Understanding digital Transformation: A Review and a research Agenda", Journal of Strategic Information Systems 28(2), 2019, pp. 118-144.

[50] Wade, M., and J. Hulland, "Review: The resourcebased view and information systems research: Review, extension, and suggestions for future research", MIS Quarterly: Management Information Systems 28(1), 2004, pp. 107-142.

[51] Webster, J., and R.T. Watson, "Analyzing the Past to Prepare for the Future: Writing a Literature Review.", MIS Quarterly, 2002, pp. xiii-xxiii.

[52] Wessel, L., A. Baiyere, R. Ologeanu-Taddei, J. Cha, and T.B. Jensen, "Unpacking the Difference between Digital Transformation and IT-enabled Organizational Transformation", Journal of the Association for Information Systems(March), 2020, pp. 1-57.

[53] Whelan, E., W. Golden, and B. Donnellan, "Digitising the R\&D social network: Revisiting the technological gatekeeper", Information Systems Journal 23(3), 2013, pp. 197-218.

[54] Woodard, J., N. Ramasubbu, F.T. Tschang, and V. Sambamurthy, "Design Capital and Design Moves: The Logic of Digital Business Strategy", MIS Quarterly 37(2), 2013, pp. 537-564.

[55] Yoo, Y., "Computing in everyday life: A call for research on experiential computing", MIS Quarterly: Management Information Systems 34(2), 2010, pp. 213-231.

[56] Yoo, Y., R.J. Boland, K. Lyytinen, and A. Majchrzak, "Organizing for Innovation in the Digitized World", Organization Science 23(5), 2012, pp. 1398-1408.

[57] Yoo, Y., O. Henfridsson, and K. Lyytinen, "The new Organizing Logic of digital Innovation: An Agenda for Information Systems Research", Information Systems Research 21(4), 2010, pp. 724-735. 